удК 332.1

М. Л. Багайников

Байкальский государственный университет, г. Иркутск, Российская Федерация

\title{
ГЕОЭКОНОМИЧЕСКИЕ АСПЕКТЫ РАЗВИТИЯ ЭЛЕКТРОЭНЕРГЕТИЧЕСКОГО ХОЗЯЙСТВА БАЙКАЛЬСКОГО РЕГИОНА
}

\begin{abstract}
АНнотАЦИя. В статье рассматриваются вопросы развития электроэнергетического хозяйства Байкальского региона как одного из направлений реализации его геоэкономического потенциала. Последовательная интеграция энергосистемы региона в национальные и международные энергетические системы будет способствовать реализации природно-ресурсного потенциала региона и эффективной идентификации его хозяйства в мировом геоэкономическом пространстве. При этом Байкальский регион рассматривается как целостная трансграничная территориальная структура, в основе вычленения которой лежит бассейновый подход, поскольку именно гидросферные объекты формируют его хозяйственный ландшафт. Также в статье указывается на то, что дальнейшее наращивание использования в электроэнергетике гидроресурсов региона, если и не достигла своего предела, то экологически нецелесообразно, поскольку это негативно влияет на экосистему Байкальского бассейна и нарушает принцип бассейновой солидарности. В качестве меры по развитию электроэнергетического комплекса региона, обоснованно предлагается развитие угольной генерации на основе экологически более безопасного водоугольного топлива.

кЛючЕВЫЕ словА. Региональная экономика; водоугольное топливо; геоэкономика; Байкальский регион; геоэкономический регион.

ИНФОРМАЦИЯ О СТАТЬЕ. Дата поступления 06 декабря 2017 г.; дата принятия к печати 19 марта 2018 г.; дата онлайн-размещения 09 апреля 2018 г.
\end{abstract}

M. L. Bagaynikov Baikal State University, Irkutsk, Russian Federation

\section{GEO-ECONOMIC ASPECTS OF POWER INDUSTRY DEVELOPMENT OF BAIKAL REGION}

ABSTRACT. The article considers the development issues of the electric power economy in the Baikal region as one of directions for implementing its geo-economic potential. The consistent integration of the region's energy system into the national and the international energy systems will facilitate the implementation of the regional natural and resource potential and the effective identification of its economy in the world geo-economic space. At the same time, the Baikal region is considered to be an integral transboundary territorial structure based on the basin approach, since it is the hydrosphere objects that form its economic landscape. The article also points out that the further increase of the use of the regional hydro resources in the electric power industry is ecologically inexpedient or it even has reached its limit, since this adversely affects the ecosystem of the Baikal Basin and violates the principle of basin solidarity. It is reasonably proposed to develop the coal-fired generation based on ecologically safer water-coal fuel, as a measure for developing the regional electric power complex.

KEYWORDS. Regional economy; water-coal fuel; geo-economics; Baikal Region; geo-economic region.

ARTICLE INFO. Received December 06, 2017; accepted March 19, 2018; available online April 09, 2018.

\section{Baikal Research Journal}


Одной из ведущих отраслей экономики Байкальского региона, определяющей его хозяйственной ландшафт, является электроэнергетика, сформированная на базе гидроэнергии р. Ангара и углей угленосных районов Иркутской области, Бурятии и Монголии, а также угольных месторождений Красноярского и Забайкальского края.

На территории Байкальского региона электроэнергию вырабатывают четыре гидроэлектростанции (Братская ГЭС, Иркутская ГЭС, Усть-Илимская и Богучанская ГЭС - на р. Ангара и Мамаканская ГЭС - на р. Мамакан, находящиеся в административных границах Иркутской области и Красноярского края) общей мощностью 12,5 ГВт, а также 17 теплоэлектростанций с суммарной энергетической мощностью - 4,1 ГВт. Отметим, что Богучанская ГЭС расположена на территории Красноярского края (Кежемский район), однако сток реки на ее месте зарегулирован оз. Байкал, Иркутским, Братским и Усть-Илимским водохранилищами. То есть с точки зрения гидрографии станция находится на территории Байкальского региона (Ангаро-Байкальского бассейна).

На территории Республики Бурятия эксплуатируются Гусинозерская ГРЭС и ТЭЦ-1 в г. Улан-Удэ, общей энергетической мощностью 1,3 ГВт. Таким образом, суммарная мощность электрогенерирующих предприятий Байкальского региона (в пределах Российской Федерации) составляет порядка 15 ГВт, из которых более $63 \%$ мощности приходится на гидроэнергетику. Более $90 \%$ энергогенерирующих мощностей Байкальского региона расположено на территории Иркутской области, что объясняет низкую энергообеспеченность его восточной провинции и накладывает серьёзные ограничения на уровень её экономического развития.

Гидрологические особенности и ландшафт Бурятии и Монголии (значительная территория республики относится к бассейну оз. Байкал) затрудняют строительство и эксплуатацию ГЭС, хотя вопросы, касающиеся их строительства рассматривались ранее и рассматриваются в настоящее время. Так, например, вновь поднимается вопрос о необходимости строительства Мокской ГЭС ${ }^{1}$, что изначально было связано с началом строительства Байкало-Амурской магистрали, однако экономический спад 1990-х гг. оставил проект без финансирования. Устойчивый рост энергодефицита в Бурятии вновь актуализировал этот вопрос, более того, в 1997 г. было подготовлено технико-экономическое обоснование проекта, а в 2007 г. ОАО «РусГидро» (на тот момент «ГидроОГК») была учреждена специальная «Корпорация развития Забайкалья». Проект был включен в число инвестиционных программ «РусГидро» однако финансово-экономический кризис конца $2000-$ х гг. вновь отложил его реализацию на неопределенный срок. Помимо самой ГЭС планировалось также строительство ее контррегулятора - Ивановской ГЭС, проектной мощностью $210 \mathrm{MBT}^{2}$. Актуальной проблемой эксплуатации существующей энергосистемы Бурятии является также значительный объем технических и коммерческих потерь в структуре энергопотребления, достигающих 13,5 \% к общему полезному отпуску электроэнергии [1].

Одним из направлений повышения уровня обеспеченности республики электроэнергией может стать строительство и ввод в эксплуатацию второй очереди ТЭЦ - 2 (г. Улан-Удэ), установленной мощности 840 МВт. В настоящее время станция работает в режиме пиковой котельной и вырабатывает только тепло (380 Гкал ч). Наличие в Бурятии 10 месторождений бурого и 4 месторождений каменного угля, придает этому мероприятию экономический смысл.

\footnotetext{
${ }^{1}$ Гидроэлектростанция на р. Витим (правый приток р. Лена) мощностью 2010 МВт. После пересмотра проекта планируемая мощность была снижена до 1200 МВт.

${ }^{2}$ URL: http://blog.rushydro.ru/?p=2594.
}

\section{Baikal Research Journal}


Большой интерес вызывает электроэнергетический комплекс Республики Монголия, хозяйство которой все активнее участвует в международных экономических отношениях, имея при этой очень тесные экономические связи с Россией. Ядро энергосистемы Монголии составляют пять теплоэлектростанций мощность от 20 до 480 МВт, которыми вырабатывается более 94\% всей электроэнергии. Около 70\% всей вырабатываемой электроэнергии приходится на ТЭЦ-4 (установленной мощности 480 МВт), расположенной в г. Улан-Батор. Таким образом, установленная мощность электростанций энергосистемы республики составляет 825 МВт, в то время как располагаемая не превышает 648 МВт.

В условиях стремительного развития промышленного комплекса Монголии, прежде всего, горнодобывающей отрасли, представленной предприятиями угольной, золотодобывающей, медно-молибденовой, плавикошпатовой и другими производствами, предъявляются повышенные требования к электропотреблению и требует ввода в эксплуатации новых энергогенерирующих мощностей. Кроме того оборудование функционирующих сегодня электростанций физически и морально стареет, создавая предпосылки для возникновения дефицита мощности, особенно в зимние максимумы. Например, пиковая мощность зимнего максимума может достигать 800 и более МВт, поэтому недостающая мощность обеспечивается импортом из иркутской энергосистемы. Однако в дальнейшем потребность в электроэнергии будет только возрастать. По данным Министерства минеральных ресурсов и энергетики МНР, даже в условиях минимального роста экономики, электропотребление к 2025 г. возрастет по сравнению с 2010 г. почти в 5 раз. В целом же национальная потребность в электрической мощности в период с 2014 по 2030 гг. может составить от 1500 до 3000 МВт [2]. Это подтверждает необходимость коренной модернизации национальной энергосистемы и формирования единого, в рамках Байкальского региона и его водосборной системы, энергетического хозяйства, базирующегося, в том числе на принципах бассейновой солидарности, способного значительно повысить уровень энергетической и эколого-экономической безопасности территории.

Для улучшения положения в сфере электроэнергетики властями Монголии рассматриваются планы строительства целого ряда электростанций. Среди проектов, имеющих особую значимость для страны, можно отметить: 1) ТЭЦ-5 г. Улан-Батора, мощностью 800 МВт; 2) электростанция на меднорудном месторождении Оюутолгой, проектной мощности 350-450 МВт; 3) электростанция на угольном месторождении Тавантолгой мощностью 20 МВт; электростанция на угольном месторождении Боорэлжуут мощностью $300 \mathrm{MBт} ; 4)$ мощная экспортная электростанция на угольном месторождении Шивэ-Овоо мощностью 4800 МВт; 5) ряд других станций суммарной проектной мощности примерно 50 МВт [3].

Помимо теплоэлектростанций, в рамках решения задач повышения энергообеспеченности, на территории Монголии планируется строительство ряда ГЭС на реках Селенга, Артсат, Орхон. Крупнейшим гидротехническим сооружением, согласно планам, должна стать ГЭС «Шурэн» на р. Селенга. Поскольку оз. Байкал является уникальным природным объектом, отнесенным ЮНЕСКО ${ }^{3}$ к списку объектов всемирного наследия, то возможные экологические риски от строительства ГЭС в его водосборной системе требует самой тщательной проработки. Кроме того, в 2013 г. был утвержден проект строительства Эгийской ГЭС (р. ЭгийнГол, левый приток р. Селенга), с расчетной мощностью 200 МВт, которая может стать крупнейшим гидроэнергетическим объектом Монголии. Однако реализация монгольских гидроэнергетических проектов в водосборной системе оз. Байкал, в

\footnotetext{
${ }^{3}$ Учреждение $\underline{\mathrm{OOH}}$ по вопросам образования, науки и культуры.
}

\section{Baikal Research Journal}


настоящее время, не имеет перспектив реализации, поскольку натолкнулось на активное противодействие российской стороны и экологов.

Поскольку строительство ГЭС сопряжено с экологическими рисками и необходимость поиска компромиссов с российской стороной, то развитие теплоэнергетики остается одним из главных приоритетов. Тем более, что Монголия обладает огромными запасами угля (геологические запасы угля превышают 160 млрд т), достаточно равномерно распределенными по территории страны. Крупнейшим месторождением Монголии с подтвержденными запасами коксующегося угля $\left(6,4\right.$ млрд т) является месторождение Тавантолгой ${ }^{4}$ К Кроме того можно отметить следующие месторождения: «Хошоот» - месторождение коксующегося угля (производственный резерв - 97 млн т); «Тугруг нуур» - месторождение бурого угля (геологические запасы - 6,8 млрд т); «Шивээовоо» - месторождение бурого угля (производственный резерв - 564,1 млн т); «Баянжаргал» - месторождение бурого угля (предварительные запасы -347 млн т) и целый ряд других ${ }^{5}$.

Институционализация Байкальского геоэкономического региона как глобального актора и участника процесса геоэкономической конкуренции, должна содержать в себе конкретные проекты создания отраслевых и межотраслевых хозяйственных комплексов, предусматривающих их активную интеграцию с хозяйственными комплексами других стран и регионов. В сфере электроэнергетики геоэкономическим проектом ближайшей перспективы можно считать создание межгосударственной электроэнергетической системы, объединяющей энергосистему Байкальского региона России с ЦЭС (Центральной энергосистемой) Монголии.

Участники международных отношений в сфере электроэнергетики в целом признают необходимость создания единой энергосети, сначала, локальной, объединяющей только регионы сопредельных стран, в дальнейшем постепенно расширяющей свои границы, вливаясь в масштабные международные электроэнергетические проекты. Поэтому следующим этапом развития региональной энергосистемы может стать включение региональной энергосети в перспективные национальные и международные энергосистемы, например, энергомост «Сибирь - Урал - Центр» и азиатский международный мегапроект - «Энергетическое суперкольцо», объединяющее энергосистемы России, Монголии, Китая, Республики Корея и Японии.

Проект энергомоста «Сибирь - Урал - Центр» и место, которое может в нем занять энергосистема Байкальского региона, является вопросом, имеющим важное значение в контексте стратегического развития национальной энергетической инфраструктуры и инфраструктуры ее региональных подкомплексов. Актуальность этого вопроса обусловлена необходимостью создания единого социально-экономического пространства путем хозяйственной интеграции всех регионов России, в т. ч. Восточной Сибири и Дальнего Востока, который может быть решен с помощью формирования транспортно-энергетической и информационно-институциональной инфраструктуры [4]. Хозяйственная интеграция предполагает также отказ от концепции ресурсного глобализма в пользу регионализма. Данный постулат в полной мере соответствует последним мировым тенденциям, когда мировое хозяйство постепенно фрагментируется по региональному принципу, а мирохозяйственное взаимодействие осуществляется, преимущественно, между глобализироваными региональными хозяйственными структурами.

Разработка этого масштабного инфраструктурного проекта по переброске электроэнергии была начата в 1970-х гг. в СССР. В 1986 г. по территории Казахстана

${ }^{4}$ URL: http://isem.irk.ru/AEC-2012/pres/S4-2\% 20pres.pdf.

${ }^{5}$ Монгольская геология и полезные ископаемые. URL: http://mongolnow.com/mn-geo.html. (Дата обращения: 05.11.2017).

\section{Baikal Research Journal}

электронный научный журнал Байкальского государственного университета 
была проложена первая в мире ЛЭП сверхвысокого напряжения (1150 КВт), которая должна была стать частью энергомоста из Азии в Европу. Однако крах СССР и последовавшая за этим череда экономических «преобразований», привели к тому, что реализация проекта была полностью свернута. Реинкарнация мегапроекта на ее идейном уровне произошла в 2000 -х гг., когда была признана неэффективность существующей разрозненной национальной энергосистемы с высоким уровнем дифференциации, как по уровню энергообеспеченности потребителей разных регионов (предприятий и населения), так и по величине тарифов. Известно, что система централизованного энергоснабжения покрывает лишь треть территории страны, тогда как потребность в электроэнергии на большей части территории России, покрывается автономными энергоустановками, работающими на дорогостоящем привозном топливе [5]. Согласно прогнозу Министерства энергетики РФ, к 2030 г. потребность экономики страны составит порядка 60 ГВт, 2/3 из которых придется на долю Центральной России. Уже сегодня европейская Россия и Урал испытывают недостаток мощности $(11,25$ ГВт или $7,8 \%)$, что актуализирует проблему модернизации региональной и национальной энергосистемы [6]. Поэтому реализация проекта переброски электроэнергии с востока на запад страны лишь вопрос времени.

Расчеты, проведенные по методикам ФСК ЕЭС, показали наличие пре-имуществ проекта переброски электроэнергии из Сибири в Европу в долгосрочной перспективе, по сравнению с транспортировкой топлива для существующих и перспективных электростанций, работающих на угле и газе [7]. Кроме того, поставки электроэнергии позволят существенно разгрузить железную дорогу, благодаря сокращению объемов внутренних перевозок угля, что благоприятно скажется на транзитных возможностях территории России в условиях усиления глобальной конкуренции в сфере трансконтинентальных грузоперевозок.

В перспективе целесообразным видится прокладка энергомоста в виде высоковольтной линии (в т. ч. постоянного тока) не только в западном направлении, но и в восточном - к побережью Тихого океана, а оттуда к Японским островам, что позволит замкнуть планируемое азиатское энергетическое кольцо. При этом северная дуга в обе стороны будет обеспечиваться энергогенерирующими мощностями Байкальского региона, что позволит реализовать имеющийся геоэкономический потенциал.

Существует точка зрения, согласно которой участие энергетического комплекса Байкальского региона в масштабных проектах трансконтинентального уровня позволит полнее использовать энергетический потенциал, тем более, что он обладает значительными мощностями дешевой гидрогенерации, которые имеют высокий не только внутренний, но и внешний спрос, а после выхода на полную мощность Богучанской ГЭС регион станет энергоизбыточным [8].

Развитие взаимоотношений в области электроэнергетики может стать институциональной основой формирования Байкальского геоэкономического региона, использующего свои гидроресурсы и запасы энергетических полезных ископаемых, для самоидентификации в глобальном геоэкономическом пространстве. Это позволит продвинуться на пути создания восточного геоэкономического полюса России, играющего важную роль в решении задач становления народнохозяйственного комплекса страны в целом.

Однако объективные экологические ограничения в направлении более активного использования гидроресурсов бассейна, требуют диверсификации источников генерации. Экосистема р. Ангара, гидроресурсы которой эксплуатируются наиболее активно, уже подверглась существенным трансформациям, начиная с локальных климатических изменений: влажности воздуха, его среднегодовой температу-

\section{Baikal Research Journal}

электронный научный журнал Байкальского государственного университета 
ры, естественного движения водных и воздушных масс; заканчивая изменением ихтиофауны. На грани исчезновения оказались такие реофильные виды рыб как осетр, стерлядь, ленок, таймень, сиг и др. В переделах водохранилищ, речная ихтиофауна была постепенно вытеснена лимнофильной, свойственной водоемам со стоячей водой (плотвично-окуневыми ихтеоцинозами), в результате чего «возникли новые, обеднённые по сравнению с исходной, фауны рыб» [9, с. 59]. Оз. Байкал выполняет функцию главного источника биоинвазий, но барьеры в виде плотин ГЭС значительно ограничивают развитие этого естественного процесса.

Кроме того, в результате строительства Ангарского каскада ГЭС был нанесен серьезный урон хозяйству региона, прежде всего сельскому и лесному, а также культурно-историческому наследию. Известно, что в результате строительства Иркутской, Братской и Усть-Илимской ГЭС было затоплено более 194 тыс. га сельхозугодий, около 500 населенных пунктов, несколько десятков миллионов кубометров леса. Масштабное гидротехническое строительство повысило уровень воды в оз. Байкал и привело к затоплению еще порядка 100 тыс. га земли, 127 населенных пунктов, в т. ч. 9 городского типа, располагавшихся по берегам водоема. Строительство Богучанской ГЭС привело к затоплению еще 1494 км I земель, из которых 19,8 \% пришлось на сельхозугодия и 75,7 \% на лесные угодья, а также стоило Красноярскому краю и Иркутской области потерей 29 и 4 населенных пунктов соответственно (целый ряд из которых имел многовековую историю), а вместе с ними были утрачены ценнейшие исторические свидетельства жизни старожильческого населения Нижнего Приангарья. Также под водой оказались известные наскальные рисунки Аплинского порога; невозвратной стала потеря целого ряда артефактов эпохи палеолита - Ангарских писаниц, изученных и скопированных А. П. Окладниковым, ныне погребенных на дне Братского водохранилища. На дне Братского и Усть-Илимского водохранилищ оказались множество других исторических свидетельств жизни людей каменного века, так и не дождавшихся более подробного изучения.

Поскольку гидропотенциал р. Ангара оценивается в 94 млрд КВт ч, в то время как действующие станции ${ }^{6}$, вырабатывают порядка 65,3 млрд КВт ч, то в 2006 г. были начаты проектные работы по оценке строительства пятой ступени Ангарского каскада ${ }^{7}$ - Мотыгинуой ГЭС. Согласно предварительным расчетам при вариантах значений НПУ (нормальный подпорный уровень) от 123 до 129 м. общая площадь затопленных земель может составить от 10520 до 17394 га, из них земли сельхозугодий — от 1691 до 2324 га, земли поселений от 64 до 134 га, площадь лесов - 8500 до 12800 га $^{8}$.

Г. И. Медведев, Н. Е. Бердникова и др. отмечают, что сегодня «...Ангара прекратила существование как природный композитный объект-феномен широкого междисциплинарного научного изучения, многообразного хозяйственного и культурного освоения, глубокого нравственного, патриотическ ого, эстетического воспитания», поскольку протяженность участков сохранившегося речного течения между водохранилищами составляет всего 850 км. Более того, «...с вводом в эксплуатацию Кодинской (Богучанской) и Мотыгинской ГЭС Россия XX-XXI вв. довершит уникальную государственную (межрежимную!) акцию - полное плановое техногенное уничтожение одной из оригинальнейших, красивейших рек

\footnotetext{
${ }^{6}$ Включая Богучанскую ГЭС, вышедшую на полную мощность в 2015 г.

${ }^{7}$ Название проектируемой ГЭС пока официально не существует. Используются такие наименование как Гребенская ГЭС, Мотыгинская ГЭС или Выдумская ГЭС.

${ }_{8}^{8}$ Обоснование инвестиций в строительство Мотыгинской ГЭС на p. Ангаpe. URL: http://www. rushydro.ru/file/main/global/company/invest/investprojects/6276.html/OVOS_MoGES_Kniga-1.pdf. (Дата обращения: 16.06.2017).
}

\section{Baikal Research Journal}


мира и ее вместилища - Большого разлома - с богатейшей летописью геологических событий и палеогеоморфологических построений протяженностью почти в 1 млрд лет (!), с миллионами былых человеческих судеб, овеществленных в ископаемых остатках археологических культур» [10, с. 40].

При решении задач повышения энергообеспеченности территории, а также реализации ресурсного потенциала региона через участие в международных энергомаршрутах, внимание следует уделить развитию альтернативных гидроэнергетике видов генераций. Прежде всего, это касается развития теплоэнергетики, что обосновано наличием в регионе значительных запасов угля. В настоящее время на долю угля приходится лишь 23,1 \% мирового потребления всех первичных источников энергии. Однако при этом мировые запасы угля в 5 раз превышают совокупные запасы нефти и газа ${ }^{9}[11]$. Однако современная угольная электроэнергетика России по сравнению с газовой и гидроэнергетикой, оказывает заметно большее негативное воздействие на антропоэкологические системы. В частности, вредные выбросы российских ТЭС примерно в 50 раз превышает нормы ЕС, при этом их КПД в среднем ниже на $10 \%$, а потребление топлива на старых станциях выше примерно на 30 \% [12]. Также отечественные ТЭС потребляют порядка $90 \%$ низкокачественных, необогащенных углей, что связано с особенностями основного и вспомогательного котельного оборудования, установленного, преимущественно, еще в СССР и спроектированного под угли конкретных месторождений. Даже частичное замещение проектного угля другими марками требует сложных и дорогостоящих мероприятий [13].

В настоящее время серьезной экологической проблемой, связанной с эксплуатацией российских угольных ТЭС является накопление значительных объемов золошлаковых отходов (1,5 млрд т), требующих дополнительного землеотвода, пыление которых загрязняют атмосферу, а в результате фильтрации водорастворимых тяжелых металлов - гидросферу и не только в зоне расположения, но и далеко за ее пределами $[14 ; 15]$. Но главные экологические угрозы связаны с выбросами в атмосферу $\mathrm{CO}$, оксидов серы, азота и летучей золы. Актуальной остается проблема радиационного загрязнения территорий, прилегающих к угольным электростанциям [13].

Одним из направлений развития теплоэнергетики может стать широкое внедрение водоугольного топлива (ВУТ). По сравнению с традиционными способами пылеугольного и слоевого сжигания угля, его использование позволяет существенно снизить выбросы загрязняющих веществ. Например исследования, проеденные С. А. Дужих и др. показали, что использование ВУТ позволяет снизить в выбросах содержание пыли и сажи $\left(г / \mathrm{M}^{3}\right)-$ в 100-300 раз; $\mathrm{SO}_{2}\left(\mathrm{Mr} / \mathrm{M}^{3}\right)-$ в 12-50 раз; $\mathrm{NO}_{\mathrm{x}}\left(\mathrm{мг} / \mathrm{M}^{3}\right)-$ в 6-15 раз; $\mathrm{CO}\left(\mathrm{мг} / \mathrm{M}^{3}\right)-$ в 6-50 раз, при этом доля несожжённого угля в золе составляет не более 3-4 \% [16].

ВУТ является высокореакционным высококачественным и экологически чистым органическим топливом, пригодным к использованию как на крупных ТЭС с обеспечением трубопроводной доставки на достаточно большие расстояния, так и на ТЭС малой мощности (менее 1-2 МВт) с порционной доставкой топлива. Выбросы при использовании такого топлива, согласно вышеупомянутым авторам, не содержат монооксид углерода, вторичные углеводороды, бенз(а)пирен и сажу, а также «летучую» золу. При этом выбросы в атмосферу твердых частиц, оксидов серы и азота в районе расположения ТЭС не превышает установленные ПДН [17].

Неоспоримым преимуществом ВУТ является возможность использования углей любых марок, начиная с обводненных бурых углей, заканчивая антрацитами. Это позволяет унифицировать угольное топливо и упростить логистику его

${ }^{9}$ World Energy Assessment. UNDP. New York, USA 2000.

\section{Baikal Research Journal}

электронный научный журнал Байкальского государственного университета 
доставки. Процесс производства данного вида топлива также не требует существенной переоснастки существующих обогатительных фабрик, поскольку для его производства требуются дробилки и грохоты, а для вторичного дробления при производстве гранулированного порошка и пылевидного угля - роторные и молотковые дробилки. Для обогащения угля в наличии имеются сепараторы и гидроциклоны, а также различные устройства для смешивания угля с различными реагентами (как правило, пластификаторами для снижения вязкости, повышения гидрофильности и увеличения сольвантных оболочек вокруг частиц угля).

В ходе проведения экспериментальных исследований, Л. И. Мальцев отмечает, что степень выгорания ВУТ достигает 95-99 \%, что почти вдвое больше чем при сжигании сухого угля. Однако испытания технологии в «большой» энергетике показали недоработку целого ряда составляющих её компонентов:

- относительная сложность и дороговизна, при современных технологиях производства, подготовки ВУТ;

- нестабильность фракционного состава и характеристик конечной продукции;

- низкий ресурс сопел форсунок и общий недожог топлива [18].

Однако выявленные технологические проблемы позволили локализовать задачи доведения процесса до приемлемого эколого-экономического уровня. Кроме того, данная технология экономически эффективна, прежде всего вследствие снижения затрат на транспортировку топлива (замена железнодорожного транспорта на трубопровод), возможность использования низкосортных местных углей и общего повышения КПД работы электростанций (до 68-70\%), а по отверждению некоторых специалистов - до 80-85\% [19; 18].

Применение ВУТ в электроэнергетике позволяет существенно снизить экологические риски ввиду значительного сокращения отходов по сравнению с традиционными технологиями, что особенно ценно для уникальной экосистемы Байкальского региона. Развитие ВУТ, по нашему мнению, может иметь большие перспективы, с одной стороны, вследствие наличия в регионе значительных запасов угля, с другой, ввиду необходимости развития электроэнергетической инфраструктуры территории (с целью сгладить неравномерность в энергообеспеченности различных ее частей) и, следовательно, реализации природно-ресурсного потенциала. Поскольку наиболее сложная ситуация в сфере энергообеспеченности наблюдается в Бурятии и Монголии, то формирование развитой системы ТЭС, работающих на экологически чистом угольном топливе и его производных, может дать мощный импульс для их динамичного социально-экономического развития.

\section{Список использованной литературы}

1. Борталевич С. И. Методические аспекты развития энергохозяйства Республики Бурятия в контексте энергетической программы страны / С. И. Борталевич // Вестник Бурятского государственного университета. - 2011. - № 2. - С. 95-98.

2. Энергетическое сотрудничество Монголии и России: современное состояние и стратегические направления / Н. И. Воропай [и др.] // Пространственная экономика. 2013. - № 3. - C. 108-122.

3. Энхжаргал X. Перспективные направления развития электроэнергетической системы Монголии / Х. Энхжаргал, С. Батмунх, В. А. Стенников // Энергетическая политика. 2012. - № 4. - С. 70-81.

4. Бушуев В. В. Транспортно-энергетическая инфраструктура Евразии как основа ее устойчивого развития / В. В. Бушуев // Экономика региона. - 2013. - № 4 (36). C. $142-150$.

5. Мелокумов Е. В. Автотрофно-экологическая эффективность (полезность) и развитие альтернативной энергетики в проектировании экономики нового типа / Е. В. Мелокумов // Лесной вестник. - 2011. - № 2 (78). - С. 117-124.

\section{Baikal Research Journal}


6. Дятел Т. Сибирь на грани энергодефицита / Т. Дятел // Коммерсантъ. - 2017. 18 сент. (№ 172). - С. 7 .

7. Касаткина 3. Энергомост из прошлого / З. Касаткина // Сибирский энергетик. 2012. -23 нояб. (№ 44).

8. Ольшанников А. Провода за триллион / А. Ольшанников, Е. Шестернина // Мониторинг СМИ (приложение) - 2012. - 21 нояб.

9. Понкратов С. Ф. Инвазии чужеродных видов рыб в бассейн ангарских водохранилищ / С. Ф. Понкратов // Российский журнал биологических инвазий. - 2013. - Т. 6, № 4. C. $59-69$.

10. Ископаемые литотехнологические отложения плейстоцена и голоцена в геоморфологических ситуациях антропогена Байкальской Сибири / Г. И. Медведев [и др.] // Известия Иркутского государственного университета. Серия: геоархеология. этнология. антропология - 2012. - № 1. - С. 33-57.

11. Малышев Ю. Н. Уголь и альтернативная экологически чистая энергетика / Ю. Н. Малышев. - М. : Изд-во Акад. гор. наук, 2000. - 94 с.

12. Ханженкова Н. Реконструкция и повышение энергоэффективности тепловых электростанций / Н. Ханженкова, О. Токарев // Академия Энергетики. - 2010. - № 2. - С. 24-29.

13. Сидорова Г. П. Экологическое воздействие угольных ТЭС на окружающую среду / Г. П. Сидорова, Д. А. Крылов, А. А. Якимов // Вестник ЗабГУ. - 2015. - № 9 (124). C. $28-38$.

14. Новые «чистые» технологии сжигания угля как фактор перспективного развития угольной энергетики России / И. Е. Кожуховский [и др.] // Энергетик. - 2008. — № 7. C. $2-5$.

15. Крылов Д. А. Микроэлементы в топливе и золошлаковых отходах угольных электростанций / Д. А. Крылов // Энергетик. - 2012. - № 11. - С. 36-39.

16. Дужих С. А. Анализ экологической и экономической эффективности применения водоугольного топлива в теплоэнергетике / С. А. Дужих, А. Г. Морозов, А. Д. Маркин. Режим доступа: http://masters.donntu.org/2013/fmf/duzikh/library/article3.pdf. (Дата обращения: 12.10.2017).

17. Рубан А. Д. Перспективная топливная угольная композиция (ВУТ) может изготавливаться на ОФ / А. Д. Рубан, А. А. Кузнецов, Г. Я. Воронко // Горный информационно-аналитический бюллетень. - 2001. - № 9. - С. 183-184.

18. Мальцев Л. И. На гребне угольной волны / Л. И. Мальцев // Наука из первых рук. - 2009. - № 5 (29). - С. 14-19.

19. Пашкевич Н. В. Оценка экономической эффективности развития угольной энергетики с учетом экологического фактора / Н. В. Пашкевич, А. Н. Мартемьянова // Записки Горного института. - 2011. - Т. 191. - С. 152-157.

\section{References}

1. Bortalevich S. I. Methodical aspects of developing energy economy of Republic of Buryatia in terms of country's energy program. Vestnik Buryatskogo gosudarstvennogo universiteta $=$ Bulletin of the Buryat State University, 2011, no. 2, pp. 95-98. (In Russian).

2. Voropai N. I., Saneev B. G., Batkhuyag S., Enkhzhargal Kh. Energy cooperation of Mongolia and Russia: current status and strategic directions. Prostranstvennaya ekonomika $=$ Spatial Economics,2013, no. 3, pp. 108-122. (In Russian).

3. Enkhzhargal Kh., Batmunkh S., Stennikov V. A. Promising directions of development of the electric power system of Mongolia. Energeticheskaya politika = Energy Policy, 2012, no. 4, pp. 70-81. (In Russian).

4. Bushuev V. V. The transport and energy infrastructure of Eurasia as a basis for its sustainable development. Ekonomika regiona = Economy of Region, 2013, no. 4 (36), pp. 142-150. (In Russian).

5. Melokumov E. V. Autotrophic-ecological efficiency (utility) and development of alternative energy in projecting a new type of economy. Lesnoi vestnik = Forestry Bulletin, 2011, no. 2 (78), pp. 117-124. (In Russian).

6. Dyatel T. Siberia on the edge of energy shortage. Kommersant" $=$ Kommersant, 2017, September, 18, p. 7. (In Russian).

\section{Baikal Research Journal}


7. Kasatkina Z. Energy bridge from the past. Sibirskii energetik = Siberian Energy Man, 2012, November, 23. (In Russian).

8. Olshannikov A., Shesternina E. Wires for a trillion. Monitoring SMI (prilozhenie) = Mass Media Monitoring (annex), 2012, November, 21.

9. Ponkratov S. F. Invasion of alien fish species into basin of Angara reservoirs. Rossiiskii zhurnal biologicheskikh invazii = Russian Journal of Biological Invasions, 2013, vol. 6, no 4, pp. 59-69. (In Russian).

10. Medvedev G. I., Berdnikova N. E., Lipnina E. A., Kogai S. A., Rogovsky E. O. Fossil lithotechnological deposits of Pleistocene and Holocene in geomorphological anthropogen situations of Baikal Siberia. Izvestiya Irkutskogo gosudarstvennogo universiteta. Seriya: geoar-kheologiya. Etnologiya. Antropologiya = The bulletin of Irkutsk state university. Series «Geoarcheology. Ethnology. Anthropology,2012, no. 1, pp. 33-57. (In Russian).

11. Malyshev Yu. N. Ugol' i al'ternativnaya ekologicheski chistaya energetika [Coal and alternative ecological energy]. Moscow, Akademiya gornykh nauk Publ., 2000. 94 p.

12. Khanzhenkova N., Tokarev O. Reconstruction and increase of energy efficiency of thermal power stations. Akademiya Energetiki = Academy of Energetics, 2010, no. 2, pp. 2429. (In Russian).

13. Sidorova G. P., Krylov D. A., Yakimov A. A. Ecological impact of coal thermal power stations on the environment. Vestnik Zabaikal'skogo gosudarstvennogo universiteta $=$ Transbaikal State University Journal, 2015, no. 9 (124), pp. 28-38. (In Russian).

14. Kozhukhovsky I. E., Dmitriev A. S., Govsievich E. R., Aleshinsky R. E. New «pure» coal combustion technologies as a factor of future development in Russian coal industry. Energetik = Energetik, 2008, no. 7, pp. 2-5. (In Russian).

15. Krylov D. A. Microelements in fuel and bottom-ash waste of coal power stations. Energetik = Energetik, 2012, no. 11, pp. 36-39. (In Russian).

16. Duzhikh S. A., Morozov A. G., Markin A. D. Analysis of ecological and economic efficiency of using water-coal fuel in heat power engineering. Available at: http://masters. donntu.org/2013/fmf/duzikh/library/article3.pdf. (In Russian).

17. Ruban A. D., Kuznetsov A. A., Voronko G. Ya. Promising fuel coal composition (CWSF) can be produced on OF. Gornyi informatsionno-analiticheskii byulleten' = Mining informational and analytical bulletin, 2001, no. 9, pp. 183-184. (In Russian).

18. Maltsev L. I. On the crest of coal wave. Nauka iz pervykh ruk $=$ Science first hand, 2009, no. 5 (29), pp. 14-19. (In Russian).

19. Pashkevich N. V., Martemyanova A. N. Assessing economic efficiency of developing coal power in terms of ecological factor. Zapiski Gornogo instituta = Journal of mining institute, 2011, vol. 191, pp. 152-157. (In Russian).

\section{Информация об авторе}

Багайников Михаил Логинович - кандидат экономических наук, доцент кафедры бухгалтерского учета, анализа, статистики и аудита, Байкальский государственный университет, 664003, г. Иркутск, ул. Ленина, 11, e-mail: koterik@mail.ru.

\section{Author}

Mikhail L. Bagaynikov - PhD in Economics, Associate Professor, Chair of Accounting, Analysis, Statistics and Audit, Baikal State University, 11 Lenin St., 664003, Irkutsk, e-mail: koterik@mail.ru.

\section{Для цитирования}

Багайников М. Л. Геоэкономические аспекты развития электроэнергетического хозяйства Байкальского региона / М. Л.Багайников // Baikal Research Journal. - 2018. - T. 9, № 1. - DOI : 10.17150/2411-6262.2018.9(1).6.

\section{Reference to article}

Bagaynikov M. L. Geo-Economic Aspects of Power Industry Development of Baikal Region. Baikal Research Journal, 2018, vol. 9, no. 1. DOI: 10.17150/2411-6262.2018.9(1).6. (In Russian).

\section{Baikal Research Journal}

